\title{
Subglacial sediment textures: character and evolution at Haut Glacier d'Arolla, Switzerland
}

\author{
Urs H. Fischer, ${ }^{1}$ Bryn Hubbard ${ }^{2}$ \\ ${ }^{1}$ Laboratory of Hydraulics, Hydrology and Glaciology, ETH-Zentrum, CH-8092 Zürich, Switzerland \\ ${ }^{2}$ Centre for Glaciology, Institute of Geography and Earth Sciences, University of Wales, Aberystwyth, Ceredigion Sr23 3DB, Wales
}

\begin{abstract}
Fourteen subglacial debris samples have been recovered from the margins of, or beneath, Haut Glacier d'Arolla, Switzerland. The grain-size distributions of these sediments are presented and compared with each other as bivariate plots of percentage weight against (sieve-defined) particle size and log number of particles against log particle diameter. All of the samples recovered are composed of a broad range of clast sizes and approach self-similarity over the four orders of magnitude of grain-sizes analysed. Fractal dimensions range from 2.47 to 2.77. Sample intercomparison reveals the operation of at least two processes of textural evolution: the production of fines by in-situ weathering, interpreted in terms of abrasion associated with subglacial sediment deformation, and the loss of fines, interpreted in terms of eluviation by percolating subglacial meltwaters. These interpretations are supported and refined through comparison of the grain-size fractions gained (in the case of deformation) and lost (in the case of eluviation) with those fractions respectively generated in a laboratory-based simulation of sediment deformation and exiting the glacier suspended in the proglacial meltwater stream. While sediment deformation has the effect of increasing the fine fraction between 0 and $10 \phi$ and of raising the fractal dimension of undeformed sediments from 2.47 to 2.77, eluviation removes particles between 2 and $10 \phi$, driving the fractal dimension of deformed sediments down from 2.77 to 2.54 . These fractal dimensions are generally lower than those recorded at other comparable glaciers, consistent with the relatively low rates of sediment deformation inferred from other studies at Haut Glacier d'Arolla.
\end{abstract}

\section{INTRODUCTION}

Bivariate plots of particle size against bin weight commonly reveal that subglacial sediments are polymodal, with each mode reflecting a process of erosion that comminutes parent clasts to generate fine products of a distinctive texture. These processes have traditionally been interpreted in terms of clast crushing, typically producing sand-size, monomineralic material, and abrasion, typically producing fragments in the silt-size range detached from the edges of larger clasts. Boulton (1978) argued for the existence of a threshold particle diameter of $1 \phi(0.5 \mathrm{~mm})$ (where $\phi=-\log _{2}$ diameter, in $\mathrm{mm}$ ) on the basis of this process-form division. According to Boulton (1978), particles coarser than $1 \phi$ are predominantly produced by plucking or crushing, while finer particles are predominantly produced by abrasion. Haldorsen (1981) refined this interpretation by arguing that there could be no such unique threshold, since the size modes also reflect bedrock lithology. Haldorsen utilized a ball mill to simulate glacial abrasion and crushing, and identified "terminal grades" controlled by both erosion processes, but specific to particular bedrock lithologies.

Once produced, however, the texture of subglacial sediments may evolve further under the influence of at least two processes operating at the glacier bed. First, debris textures may continue to evolve to finer distributions under the influence of grain fracture and abrasion under a compressive load during the shear deformation of subglacial debris layers. Dreimanis and Vagners (1971) argued that a silt-size mode develops progressively in lodgement tills with distance from their source (as a surrogate for total strain). Boulton and others (1974) refined this interpretation on the basis of the analysis of tills exposed at the retreating frontal margin of Breiðamerkurjökull, Iceland. Here, a dilated, upper horizon, up to $50 \mathrm{~cm}$ thick, contained $\sim 40 \%$ silt-size material, while underlying, non-dilated sediments contained $\sim 25 \%$ silt-size material (neglecting clasts larger than $-3 \phi$ ). Boulton and others (1974) argued that the former had acquired its character during shear-related deformation, while the latter remained essentially undeformed. Significantly, Hooke and Iverson (1995) argued that the continued operation of such a process would generate a grain-size distribution in which inter-particle stresses are minimized, thereby providing the maximum cushioning for all grains. Since this geometry implies no contact between equi-sized clasts, the resulting grain-size distribution is approximately self-similar, or fractal, given by the relation:

$$
N(d)=N_{0}\left(\frac{d}{d_{0}}\right)^{-m}
$$

Here, $N$ is the number of particles of size $d ; N_{0}$ is the number of particles of reference diameter $d_{0}$, and $m$ is the fractal dimension, given by the negative slope of a double logarithmic plot of number of particles against particle diameter. The value of $m$ therefore reflects the ratio of smaller particles to larger particles over the size range analysed. Geometric considerations discussed by Sammis and others (1987) suggest that $m$ should equal 2.58. This value was consistent with a 
material from a natural fault gouge, formed by repeated grain fracture, that had a fractal dimension of 2.6. However, samples from subglacial sediment layers that are considered to have been deformed generally have fractal dimensions of 2.8 to nearly 3.0 (e.g. Fischer, 1995; Hooke and Iverson, 1995).

These higher fractal dimensions are interpreted in terms of the generation of excess fine particles by abrasion during subglacial sediment deformation, relative to a grain-size texture generated by crushing alone (Hooke and Iverson, 1995). Iverson and others (1996) investigated this process utilising a laboratory simulation of active subglacial sediment deformation. These shearing experiments revealed that fine particles are created by the failure of grain bridges as constituent grains are fractured and subsequently abraded by intergranular sliding, driving a sediment of initially uniform clast size (2-3 mm diameter) into a polymodal distribution with a fractal dimension of 2.85 .

A similar process of clast comminution may also occur within debris-rich basal ice as it deforms under intense shear close to the glacier bed. Slatt and Eyles (1981) argued that such a weathering process involves fracture propagation along intra- and inter-crystalline planes of weakness, generating a non-selective fine fraction. Accordingly, a number of investigations of the grain-size distribution of the debris entrained in basal ice reveal a strong mode in the silt-size range, that may account for up to $60 \%$ of the total measured sample weight (e.g. Lawson, 1979; Hubbard and others, 1996). Hubbard and others (1996) assessed the self-similarity and fractal dimension of sediment incorporated within the basal ice of Swiss glaciers. While these authors argued that logarithmic particle-diameter-number plots are relatively insensitive to textural variability, the fractal dimension of the basal-ice debris characteristically fell in the range 2.6 to 2.7.

A second process that may influence the textural evolution of subglacial sediments is their eluviation by percolating meltwaters. Boulton and Dent (1974) argued that percolating meltwaters are able to transport fines through glacial tills on the basis of the textural analysis of proglacial tills at Breiðamerkurjökull. Here, the proportion of silt-size material within exposed tills increased with distance from the glacier and depth within the till, reflecting the progressive eluviation of fines down through the till by percolating rainfall. Clarke (1987) hypothesized that eluviation is likely to occur laterally beneath contemporary glaciers where waters are driven through permeable sediments containing fine clasts. Hubbard and others (1995) argued for the operation of such a process on the basis of field evidence from Haut Glacier d'Arolla, Switzerland. Here, the timing and attenuation of subglacial pressure waves indicated diurnal cycles of water flow laterally out from and back to a major subglacial channel. Changes in the hydraulic gradient driving these flows were closely associated with turbidity peaks recorded at the glacier bed, providing strong evidence for the mobilization and transport of fine particles by such flows. Significantly, measured basal turbidities were systematically higher in flows driven towards the channel than in those driven away from the channel, indicating a net loss of fines from the confined subglacial sediment layer bounding the channel throughout the late melt-season period of study. This eluviated debris is inferred to be transported from the glacier as suspended load in major meltwater streams. Indeed, more generally, the very high concentrations of fine suspended sediments that characterize proglacial outflow streams bears strong testament to the removal of fine debris from the sub- glacial environment throughout the melt season (e.g. Fenn and Gomez, 1989).

Despite our general understanding of the operation of these competing processes of subglacial debris textural alteration, no study has yet attempted to identify and isolate these effects on the basis of an integrated investigation of a series of subglacial sediment samples recovered from a single, active glacier. In this paper we report on such a study undertaken at Haut Glacier d'Arolla, where subglacial sediment samples have been recovered from seven locations considered to have been influenced to differing degrees by these specific processes. Inter-sample comparison is made on the basis of particle-size--weight and particle-number-diameter plots, and differences are assessed quantitatively in the light of constrained investigations of deformation-related abrasion and meltwater eluviation.

\section{FIELD SITE AND METHODS}

Haut Glacier d'Arolla is a $4 \mathrm{~km}$ long, temperate valley glacier located at the head of the Val d'Hérens in Valais, Switzerland (Fig. 1). Recent studies of the glacier's hydrology and dynamics have included investigation of the substrate by bed penetrometry (unpublished data of U. H. Fischer) and video observations (Copland and others, 1997) through boreholes and by direct observations in basal cavities and at the glacier margin. These investigations suggest that, at least in part, the glacier rests on an unlithified bed, and that the thickness and grain-size of the sediments are spatially variable (Harbor and others, 1997).

During the 1997 summer field season, we recovered fourteen sediment samples from seven subglacial and icemarginal locations (Fig. 1). The sampling sites included the headwall at the foot of Mont Brule, exposed subglacial moraine at the eastern margin of the glacier approximately $1.5 \mathrm{~km}$ above the terminus and subglacial meltwater tunnels

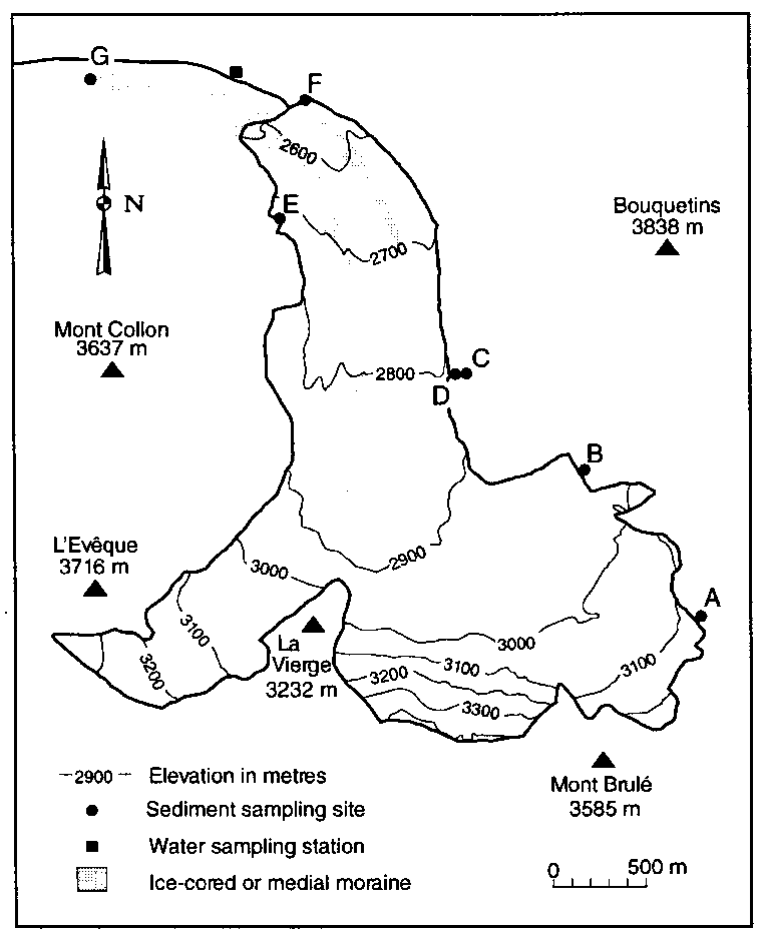

Fig. 1. Haut Glacier d'Arolla with sample locations. Labels A to $G$ refer to sample site descriptions in caption of Figure 2. 

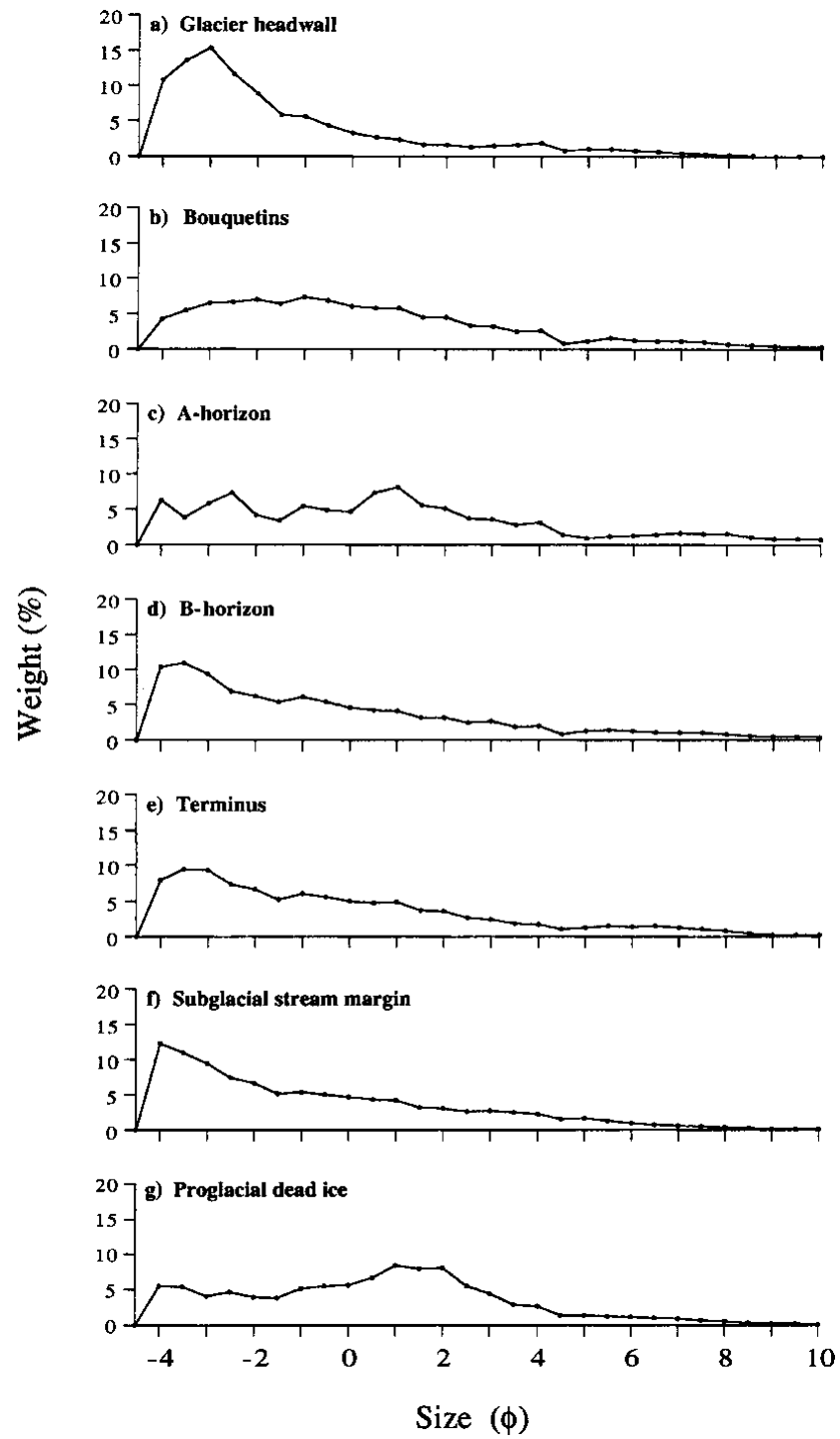

Fig. 2. Mean size-weight distributions of samples collected from: (a) the headwall below Mont Brulé; (b) the glacier margin below the Bouquetins ridge; (c) an upper horizon of exposed subglacial moraine; (d) a lower horizon of exposed subglacial moraine; (e) the bank of a western marginal stream approximately $500 \mathrm{~m}$ above the terminus; $(f)$ within a meltwater tunnel at the eastern terminus; and $(g)$ within a meltwater tunnel in dead ice.

in the terminus region. In order to sample material which was unaffected by subaerial processes such as armouring and deflation, a $\sim 30 \mathrm{~mm}$ thick surface layer was removed prior to sample recovery.

In general, only material finer than $-4 \phi(16 \mathrm{~mm})$ was analysed. We dry-sieved samples of $\sim 1.5 \mathrm{~kg}$ in the laboratory to obtain the grain-size distribution for the coarse fraction above $4 \phi(>0.063 \mathrm{~mm})$. The size distribution of the fine fraction (4-10ф, $0.063-0.001 \mathrm{~mm})$ was determined by settling analysis (SediGraph 5100, Micromeritics). We present and compare the results in two ways:

1. As plots of bin weight (percentage) against (sievedefined) particle size $(\phi)$ (Fig. 2). The curves were obtained by averaging two size distributions from sediment collected at each of the seven locations. The individual size distributions for a given sampling site deviate from each other only slightly (generally less than $3 \%$ at each $0.5 \phi$ interval). We thus consider the averaged size

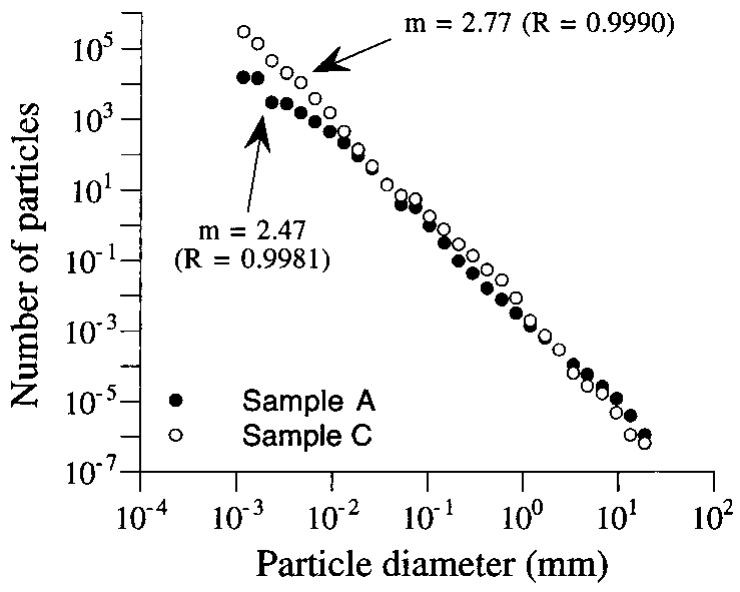

Fig. 3. Illustrative log number-log diameter plots of sample A (glacier headwall) and sample $C$ (A-horizon). The fractal dimension (m) of each texture is given by its negative slope.

distribution to be representative of the glacial environment from which the samples were taken.

2. As fractal dimensions $(m)$ of the size distributions (Fig. 3). Sediment self-similarity is indicated by the linearity of double logarithmic plots of number of particles $(N)$ against particle diameter $(d)$ and is assessed in terms of the correlation coefficient $(R)$ of the linear regression. A higher correlation coefficient points to a closer approximation of the sample texture to self-similarity. Where self-similarity is demonstrated, the negative slope of the diameter-number plot (Equation (1)) indicates a sample's fractal dimension. Significance testing of these slopes is based on $t$ tests following Williams (1984, p. 307). Results are expressed as slope error at the $90 \%$ confidence limit. We used the iterative method of Hooke and Iverson (1995) to calculate the number of particles and mean particlesize of each size bin.

\section{RESULTS}

\section{Sediment texture: general character}

Sediment textures and sampling locations are summarized in Table 1 and data are presented as particle-size--weight plots in Figure 2. Sampling locations were chosen principally on the basis of geomorphic evidence of local erosion history. Results are therefore presented below by location, progressing from the glacier headwall to the glacier terminus (Fig. 1).

\section{(a) Sample A: Glacier headwall}

Sediment collected at the headwall (sample A) is considered to be only minimally altered by post-formational subglacial erosion by deformation or eluviation. This debris is relatively coarse and consists largely of gravel-sized particles $(72 \%)$. The size--weight distribution is characterized by a strong mode located at about $-3 \phi$ (Fig. 2a). Particle-diameterabundance plots indicate a fractal dimension of $2.47 \pm 0.05$ (Fig. 3), although this relationship is weak $(R=-0.9981)$ relative to that of the other samples in this study (Table 1).

\section{(b) Sample B: Bouquetins}

Sample B sediment was recovered from an ice-marginal location about $1 \mathrm{~km}$ down-glacier of sample A. Although this sample is ice-marginal and recovered from the upper third of 
Table 1. Sampling locations and summary of sediment textures. Slope and correlation statistics relate to bivariate plots of $\log$ particle diameter against log number of particles. Slope errors represent $90 \%$ confidence limits

\begin{tabular}{lcccccc}
\hline Sample & Location & Gravel & Sand & Silt & Slope & $\begin{array}{c}\text { Corre- } \\
\text { lation }\end{array}$ \\
& & $\%$ & $\%$ & $\%$ & $\mathrm{~m}$ & $R$ \\
\hline A & Glacier headwall & 72 & 22 & 6 & $2.47 \pm 0.05$ & -0.9981 \\
$\mathrm{~B}$ & Bouquetins & 46 & 45 & 9 & $2.67 \pm 0.04$ & -0.9991 \\
$\mathrm{C}$ & A-horizon & 37 & 49 & 14 & $2.77 \pm 0.04$ & -0.9990 \\
$\mathrm{D}$ & B-horizon & 55 & 35 & 10 & $2.66 \pm 0.02$ & -0.9997 \\
$\mathrm{E}$ & Terminus & 52 & 37 & 11 & $2.64 \pm 0.03$ & -0.9992 \\
$\mathrm{~F}$ & $\begin{array}{c}\text { Subglacial stream } \\
\text { margin }\end{array}$ & 58 & 34 & 8 & $2.54 \pm 0.04$ & -0.9986 \\
$\mathrm{G}$ & Proglacial dead ice & 32 & 58 & 10 & $2.65 \pm 0.06$ & -0.9973 \\
& & & & & & \\
\hline
\end{tabular}

the glacier, we consider it has experienced slightly more subglacial erosion than sample A. There is no observable local geomorphic evidence of stream activity, such as former channels or depositional pods of sorted sands or gravels, indicating insignificant former subglacial fluvial erosion. This sample's texture is best described in terms of two modes: one broad mode centred on $-1 \phi$ and a secondary mode at $6.5 \phi$ (Fig. 2b). Percentage fractions of gravel and sand-sized particles are approximately equal ( $46 \%$ and $45 \%$, respectively). Particle-diameter-abundance plots indicate a relatively strong fractal dimension of $2.67 \pm 0.04(R=-0.9991)$.

\section{(c) Sample C: A-horizon and Sample D: B-horizon}

The exposed subglacial moraine at the eastern margin of the glacier, approximately $1.5 \mathrm{~km}$ up-glacier from the terminus and $2 \mathrm{~km}$ from the headwall, is characterized by a visibly distinct horizon separating an upper layer, up to $2 \mathrm{~m}$ thick, from the much thicker underlying material. Visual analysis of these horizons indicates a greater degree of preferential clast alignment and a generally finer grain-size in the upper layer. While a number of processes (such as the deposition of finer material during readvance) could be invoked to explain this feature, we adopt the simpler working hypothesis that the section represents a relatively thick, deformed A-horizon overlying a less deformed B-horizon (cf. Boulton and others, 1974). As in the cases of samples A and B, there is little local geomorphic evidence of significant former fluvial erosion. The A-horizon debris (sample $\mathrm{C}$ ) is polymodal (Fig. 2c), being dominated by a sand-sized fraction (49\%) with $37 \%$ in the gravel-size range. Significantly, this A-horizon debris also contains the largest amount of silt-sized particles (14\%) of any of the samples investigated in the present study. In contrast, the size distribution of the B-horizon debris (sample D) is dominated by a large fraction of gravel-sized particles $(55 \%)$, with only $35 \%$ in the sand-size range (Fig. 2 d). Particle-diameter-abundance plots indicate relatively strong fractal dimensions of $2.77 \pm 0.04(R=-0.9990)$ for the A-horizon (Fig. 3) and 2.66 $\pm 0.02(R=-0.9997)$ for the B-horizon.

\section{(d) Sample E: Terminus}

Approximately $500 \mathrm{~m}$ up-glacier of the terminus, a marginal stream flows via a tunnel beneath the western margin of the glacier. Sample E sediment was recovered from the bank of the stream bed as it cut into morainic material at the entry point of the stream beneath the ice. Despite the presence of a stream at this location, there was little visual evidence for sediment sorting. The size distribution of this sample $(52 \%$ gravel and $37 \%$ sand) is consistent with this interpretation (Fig. 2e), being similar to that of sample D (B-horizon) recovered about $1 \mathrm{~km}$ up-glacier. The particle-diameter-abundance plot for sample $\mathrm{E}$ indicates a fractal dimension of $2.64 \pm 0.03(R=-0.9992)$, similar to that for sample D.

\section{(e) Sample F: Subglacial stream margin}

Sediment collected from the margins of an active meltwater tunnel at the eastern margin of the glacier terminus (sample F) is considered to represent fluvially eroded and eluviated debris. This sediment appeared in the field to be devoid of fines, a characteristic that is supported by quantitative textural analysis. The sample consists largely of sands (34\%) and gravels (58\%) (Fig. 2f), with only $8 \%$ in the silt-sized fraction. Particle-diameter-abundance plots indicate a fractal dimension of $2.54 \pm 0.04(R=-0.9986)$.

\section{(f) Sample G: Proglacial dead ice}

The western part of the terminus region of the glacier is heavily debris-covered and extends approximately $1 \mathrm{~km}$ further down-valley than the eastern lobe (Fig. 1). Sediment recovered from an inactive meltwater tunnel in the western stagnant, ice-cored moraine (sample $\mathrm{G}$ ) is rich in sand-sized particles $(58 \%)$. A noticeable mode located at about $1 \phi$ can be seen in the particle-size--weight plot (Fig. 2g). Particle-diameter-abundance plots indicate a relatively weak fractal dimension of $2.65 \pm 0.06(R=-0.9973)$.

Comparison of the fractal dimensions recorded at Haut Glacier d'Arolla (Table 1) with those of other glaciers (e.g. Trapridge Glacier 2.95 (Fischer, 1995); Storglaciären 2.92, Engabreen 2.84, Ice Stream B 2.96 (Hooke and Iverson, 1995)) indicates relatively low values of $m$ for the subglacial debris at Haut Glacier d'Arolla, with the exception of samples recovered from an apparently deformed A-horizon. This comparison therefore suggests a general paucity of deformation-related abrasion products at Haut Glacier d'Arolla.

\section{Sample intercomparison}

The subglacial sediments sampled in this study are assumed to have acquired their distinctive textural characteristics in response to processes operating at the glacier sole and not in response to initial variability in, for example, bedrock lithology. The latter is considered unlikely, given the relatively uniform nature of the gneissose and schistose bedrock in the area. Sample intercomparison in terms of both grain-size distributions and fractal dimensions may be helpful in identifying the impact of abrasion, associated with subglacial sediment deformation, and eluviation by percolating subglacial meltwaters.

\section{Deformation-related abrasive production of fines}

The size distributions of the A-horizon (Fig. 2c) and B-horizon debris (Fig. 2d) clearly indicate that the upper layer of the exposed subglacial moraine at the eastern margin of the glacier is depleted in the coarse fraction and enriched in the fine fraction relative to the underlying material. The observed grain-size change is also reflected in a significant difference in fractal dimensions of the sediment sampled from these horizons. While the A-horizon sediment has a fractal dimension of $2.77 \pm 0.04$, that of the B-horizon is characterized by a value of $2.66 \pm 0.02$. High fractal dimensions generally indicate high ratios of fine particles to coarse particles over the size ranges represented. Thus, our obser- 
vation that the A-horizon debris is characterized by a higher percentage of silt-sized particles and a higher fractal dimension compared to that of the underlying B-horizon is consistent with the production of fines during the subglacial deformation of the former.

This interpretation agrees with that of Boulton and others (1974), who identified a two-layer structure within the till exposed at the retreating frontal margin of Breiðamerkurjökull. These layers were interpreted as a deformed A-horizon overlying an undeformed B-horizon on the basis of a variety of geomorphic sedimentological characteristics. Significantly, redepicting the grain-size distributions of these two layers (Boulton and others, 1974, fig. 7b and c) as double logarithmic plots of number of particles against particle diameter reveals a striking contrast in fractal dimensions between the two layers; 2.91 for the debris in the upper horizon and 2.66 in the lower horizon.

This interpretation may be investigated further by taking the texture of the debris recovered from the headwall (sample A) into consideration. The headwall sediment (Fig. 2a) is characterized by a dominant coarse fraction and a relatively low fractal dimension $(2.47 \pm 0.05)$, suggesting that the material may be bedrock which has predominantly experienced crushing-plucking rather than abrasion. We propose that such material, once formed at the glacier bed, is comminuted further by both abrasion and crushing during subsequent transport along the glacier sole in a deforming basal sediment layer. In order to assess this proposition, we compare the grain-size distribution of the headwall debris (Fig. 2a) with that of the A-horizon debris (Fig. 2c) by calculating the percentage difference between these two distributions per $0.5 \phi$ interval. The resulting plot (open circles in Fig. 4) clearly indicates that the A-horizon debris is enriched in the fine fraction $(2-10 \phi)$ compared with that recovered from the headwall.

In a laboratory-based simulation of sediment deformation, Iverson and others (1996) investigated the impact of crushing and abrasion of a granular material. Shearing and comminution of a sediment of initially uniform clast size (2-3 mm diameter) resulted in a self-similar grain-size distribution. At low strains, the production of a sand frac-

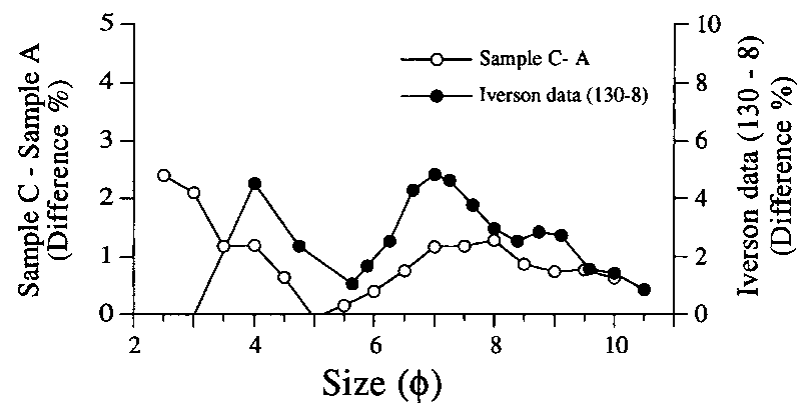

Fig. 4. Comparison of the grain-size fractions produced by insitu weathering at Haut Glacier d'Arolla with those generated in a laboratory-based simulation of sediment deformation. Open circles show the difference between the size distributions of sediment collected from the upper horizon of exposed subglacial moraine at the eastern margin (A-horizon; Fig. 2c) and from the headwall below Mont Brulé (glacier headwall; Fig. 2a). Solid circles show the difference between the grainsizes produced in a ring-shear device at high $(\sim 130)$ and low shear strains $(\sim 8)$ (Iverson and others, 1996, fig. 5a). tion with a size distribution characterized by a fractal dimension of 2.37 was observed, suggesting grain-bridge failure by crushing of constituent grains. However, continued shear-related abrasion increased the ratio of silt-sized particles to coarse particles in the sediment, driving the fractal dimension of the sediment up to 2.85. The difference between the grain sizes produced at high $(\sim 130)$ and low shear strains $(\sim 8)$ (Iverson and others, 1996, fig. 5a) has been plotted in Figure 4 (solid circles). Comparison of this laboratory-generated abrasion fraction with that resulting from the subtraction of sample A (glacier headwall) from sample C (A-horizon) in our study (open circles in Fig. 4) reveals marked similarity, strengthening our interpretation of the excess fine fraction in sample $\mathrm{G}$ in terms of in situ subglacial weathering during sediment deformation at Haut Glacier d'Arolla.

\section{Meltwater-related eluviation of fines}

The texture of the sediment from the subglacial stream margin (sample F; Fig. 2f) is characterized by a general underrepresentation of fines and a low fractal dimension $(2.54 \pm 0.04)$ relative to all other samples, but particularly relative to the A-horizon debris (sample C; Fig. 2c). The percentage difference plot for these two size distributions (open circles in Fig. 5) indicates that the debris sampled at the glacier terminus is relatively deficient in fines. This difference is consistent with our geomorphic interpretation that this sediment has been subjected to the selective removal of fine material by subglacial fluvial eluviation. The operation of such a process has been inferred by Hubbard and others (1995) based on measurements of subglacial water pressures at Haut Glacier d'Arolla.

Our interpretation that the silt-deficiency of sample F reflects meltwater winnowing may be evaluated by reference to the grain-size distribution of suspended sediment recovered from the outflow stream of Haut Glacier d'Arolla roughly $300 \mathrm{~m}$ below the terminus (Fig. 1). The mean grainsize distribution recorded over the entire 1996 summer season (a composite of over 200 individual samples; unpublished data of A. Seagren) was predominantly composed of silt-sized grains, being characterized by a large mode centred on $7 \phi$ (Fig. 5). There is also a suggestion of a secondary mode located at $4 \phi$, although it is difficult to assess the

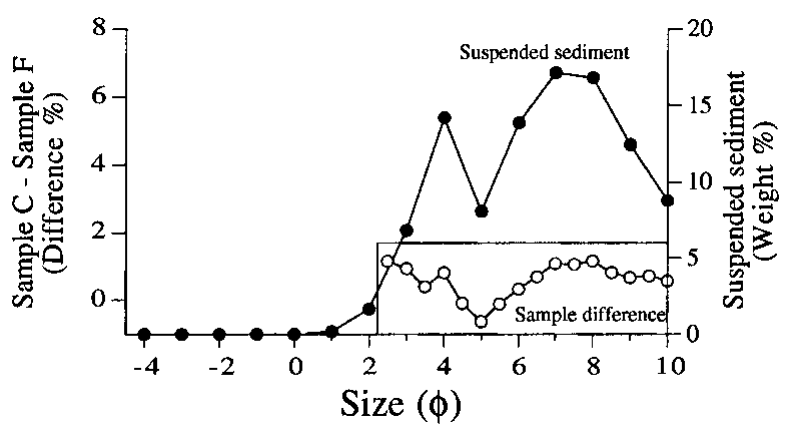

Fig. 5. Size-weight distribution of sediment suspended in the proglacial meltwater stream at Haut Glacier d'Arolla averaged over the entire 1996 summer season (Fuly-September). Inset shows the difference between the size distributions of sediment collected from the upper horizon of exposed subglacial moraine at the eastern margin (A-horizon; Fig. 2c) and from within a meltwater tunnel at the eastern terminus ( subglacial stream margin; Fig. 2f). 
significance of this mode given the $1 \phi$ sampling interval imposed by the relatively small size of the suspended-sediment samples. Since particles coarser than $2 \phi$ are noticeably absent, these suspended-sediment samples cannot be considered self-similar over the four orders of magnitude range of grain-sizes $(0.001-16 \mathrm{~mm})$ assessed in this study. The bimodal distribution of the suspended-sediment load (solid circles in Fig. 5) corresponds closely with the difference between the size distributions of debris sampled from the A-horizon (sample $\mathrm{C}$ ) and from the margins of an active subglacial meltwater stream at the terminus of Haut Glacier d'Arolla (sample F) (open circles in Fig. 5). This close agreement suggests that the texture of the A-horizon sediment may be transformed into the texture typical of the sediment from the subglacial stream margin by removal of fines through meltwater-related eluviation.

\section{CONGLUSIONS}

Subglacial sediments sampled from the margins of and beneath Haut Glacier d'Arolla are generally polymodal or composed of a broad single mode and are characterized by fractal dimensions of between 2.47 and 2.77. These values of $m$ are low, relative to those measured at other comparable glaciers. While this value cannot be exclusively related to subglacial sediment deformation, it is consistent with the inference from other studies that basal motion contributes in a relatively minor way to the overall motion of Haut Glacier d'Arolla (e.g. Hubbard and others, 1998). However, marked differences exist between sample textures that may be ascribed to the erosive action of specific subglacial geomorphic processes. Unevolved subglacial sediments are coarse, with a relatively poor degree of self-similarity and relatively low fractal dimensions (typically $2.47 \pm 0.05$ ). During transport in the deforming basal layer, shearing of such sediments may fracture clasts and generate fine-fraction particles. An inferred, deformed A-horizon sampled in the study correspondingly had the highest silt-sized content $(14 \%)$ and highest fractal dimension $(2.77 \pm 0.04)$ of all of the samples analysed. In contrast to this process of fine-particle generation, subglacial fluvial eluviation may serve to remove fines selectively from subglacial sediments. Sediments recovered from the margins of an active subglacial stream located close to the terminus of the glacier were correspondingly coarse-grained, containing only $8 \%$ silt-sized particles, and being characterized by a weak and relatively low fractal dimension of $2.54 \pm 0.04$. These interpretations were supported by the close agreement of the fine fraction gained during deformation at Haut Glacier d'Arolla with that generated in a laboratory-based simulation of sediment shearing and the fine fraction lost during eluviation at Haut Glacier d'Arolla with the fine fraction exiting the glacier as suspended load in the proglacial meltwater stream. Other subglacial samples collected from around the glacier had less well-defined geomorphic provenances, and appeared to be texturally intermediate between the grain-size distributions defined above.

While it is evident that spatial differences exist in the texture of subglacial sediments, the quantitative character of these differences and their relationships to specific geomorphic processes remain largely unconstrained. In this study we have assessed the general character of subglacial sediments beneath a small, active Alpine glacier and made a first attempt at isolating quantitatively the erosive influence of sediment deformation and fluvial eluviation at that glacier. Such spatial variability in sediment character may exert a significant influence over the local patterns of basal-stress relief and resulting glacier motion. Indeed, it may soon be possible to incorporate such information into models of ice-mass motion, given that systematic spatial patterns of both total sediment strain and fluvial eluviation may be approximated respectively from considerations of net flow distances and subglacial drainage patterns.

\section{ACKNOWLEDGEMENTS}

This work was supported by an European Science Foundation EISMINT Exchange Grant, the University of Wales Academic Support Fund, the Nuffield Foundation and an ETH-Zürich Operating Grant. We thank W. Ebenezer for his energetic assistance in the laboratory. A. Seagren kindly provided the size--weight distribution of the suspended-sediment samples. An earlier version of the manuscript benefitted greatly from the comments of D. Bahr and an anonymous reviewer.

\section{REFERENCES}

Boulton, G. S. 1978. Boulder shapes and grain-size distributions of debris as indicators of transport paths through a glacier and till genesis. Sedimentology, 25(6), 773-799.

Boulton, G. S. and D. L. Dent. 1974. The nature and rates of post-depositional changes in recently deposited till from south-east Iceland. Geogr. Ann., 56A(3-4), 121-134.

Boulton, G. S., D. L. Dent and E. M. Morris. 1974. Subglacial shearing and crushing, and the role of water pressures in tills from south-east Iceland. Geogr. Ann., 56A(3-4), 135-145.

Clarke, G. K. C. 1987. Subglacial till: a physical framework for its properties and processes. F. Geophys. Res., 92(B9), 9023-9036.

Copland, L., J. Harbor, S. Gordon and M. Sharp. 1997. The use of borehole video in investigating the hydrology of a temperate glacier. Hydrol. Processes, 11 (2), 211-224.

Dreimanis, A. and U.J. Vagners. 1971. Bimodal distribution of rock and mineral fragments in basal tills. In Goldthwait, R. P., ed. Till: a symposium. Columbus, OH, Ohio State University Press, 237-250.

Fenn, C. R. and B. Gomez. 1989. Particle size analysis of the sediment suspended in a proglacial stream: Glacier de Tsidjiore Nouve, Switzerland. Hydrol. Processes, 3, 123-135.

Fischer, U. H. 1995. Mechanical conditions beneath a surge-type glacier. (Ph.D. thesis, University of British Columbia.)

Haldorsen, S. 1981. Grain-size distribution of subglacial till and its relation to glacial crushing and abrasion. Boreas, 10(1), 91-105.

Harbor, J., M. Sharp, L. Copland, B. Hubbard, P. Nienow and D. Mair. 1997. The influence of subglacial drainage conditions on the velocity distribution within a glacier cross section. Geology, 25(8), 739-742.

Hooke, R. LeB. and N. R. Iverson. 1995. Grain-size distribution in deforming subglacial tills: role of grain fracture. Geology, 23(1), 57-60.

Hubbard, A., H. Blatter, P. Nienow, D. Mair and B. Hubbard. 1998. Comparison of a three-dimensional model for glacier flow with field data from Haut Glacier d'Arolla, Switzerland. F. Glaciol., 44(147), 368-378.

Hubbard, B. P., M. J. Sharp, I. C. Willis, M. K. Nielsen and C. C. Smart. 1995. Borehole water-level variations and the structure of the subglacial hydrological system of Haut Glacier d'Arolla, Valais, Switzerland. $f$. Glaciol., 41 (139), 572-583.

Hubbard, B., M. Sharp and W. J. Lawson. 1996. On the sedimentological character of Alpine basal ice facies. Ann. Glaciol., 22, 187-193.

Iverson, N. R., T. S. Hooyer and R. LeB. Hooke. 1996. A laboratory study of sediment deformation: stress heterogeneity and grain-size evolution. Ann. Glaciol., 22, 167-175.

Lawson, D. E. 1979. A sedimentological analysis of the western terminus region of the Matanuska Glacier, Alaska. CRREL Rep. 79-9.

Sammis, C., G. King and R. Biegel. 1987. The kinematics of gouge deformation. Pure Appl. Geophys., 125(5), 777-812.

Slatt, R. M. and N. Eyles. 1981. Petrology of glacial sands: implications for the origin and mechanical durability of lithic fragments. Sedimentology, 28(2), 171-183.

Williams, R. B. G. 1984. Introduction to statistics. London, Macmillan. 